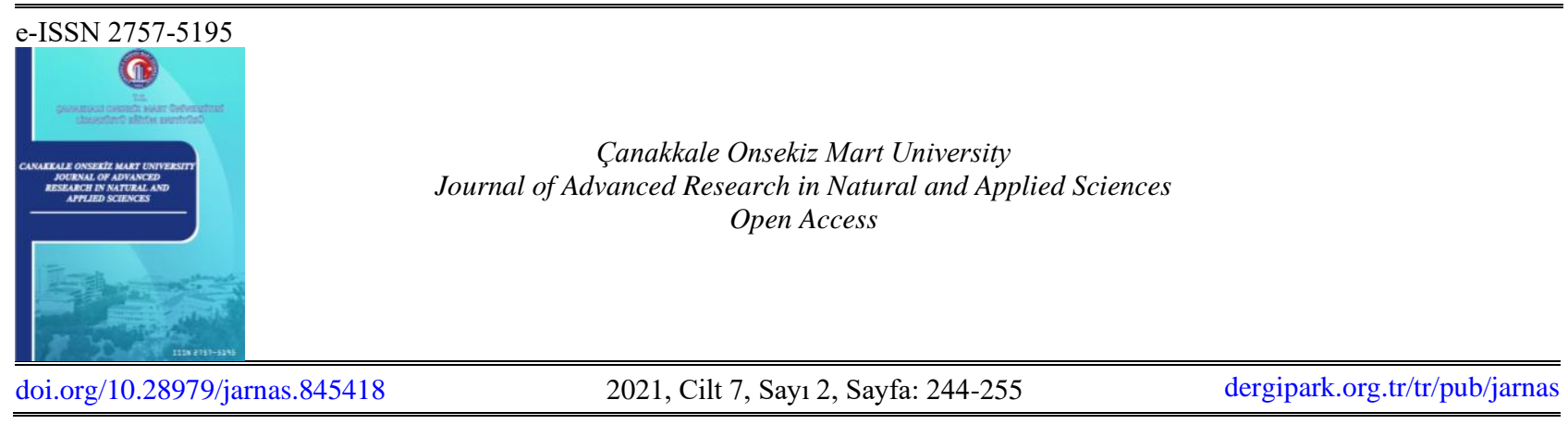

\title{
Sünek Betonarme Perde Duvarların Şekil değiştirme Esaslı Hasar Sınırları
}

\author{
Saeid Foroughi ${ }^{1{ }^{* *},}$ S. Bahadır Yüksel ${ }^{1}$
}

${ }^{1}$ Konya Teknik Üniversitesi, Mühendislik ve Doğa Bilimleri Fakültesi, İnşaat Mühendisliği Bölümü, Konya, Türkiye

Makale Tarihçesi

Gönderim: $\quad 22.12 .2020$

Kabul: $\quad 06.05 .2021$

Yayım: $\quad 30.06 .2021$

Araştırma Makalesi
$\ddot{O} \mathbf{z}$ - Betonarme perde duvarların deprem performansının belirlenmesi için doğrusal olmayan davranışlanı ile şekildeğiştirme esaslı hasar sınırları araştırılmıştır. Bu amaçla yapılan çalışmada on adet farklı parametreye sahip süneklik düzeyi yüksek perde duvar modelleri tasarlanarak çözümlemeleri yapılmıştır. Türkiye Bina Deprem Yönetmeliği 2018'de tanımlanan performans düzeyi hasar seviyeleri için perde duvarların şekildeğiștirme sınırları ile plastik dönme sınırları hesaplanmıştır. Perde duvarların şekildeğiştirmeye göre değerlendirme ve tasarımı için etkin kesit rijitliği ve akma dönme değerleri de hesaplanmıştır. Türkiye Bina Deprem Yönetmeliği 2018'e göre betonarme perde duvarların farklı performans düzeyleri için şekildeğiştirme sınırlarının hesaplanmasında; malzeme dayanımları, kesitte donatı konfigürasyonu, kullanılan sargılı betonun gerilme-şekildeğiştirme ilişkisi, kesitlerin moment-eğrilik gibi doğrusal olmayan davranışları ile plastik mafsal özellikleri dikkate alınmaktadır. Perde duvarlar için farklı performans düzeylerine göre şekildeğiştirme taleplerine karşılık gelen hasar sınırları elde edilerek değerlendirilmiştir. Perde duvar modellerinde farklı yatay donatı oranına göre hesaplanan beton toplam birim şekildeğiștirmeleri ve farkl eksenel yük oranlarındaki akma dönmesi ile plastik dönme değerleri farklı performans düzeyleri için hesaplanarak araştırılmıștır. Betonarme perde duvarlar için elde edilen moment-eğrilik ilişkilerinin üzerinde Türkiye Bina Deprem Yönetmeliği 2018'e göre hesaplanacak hasar sınırları ve bölgeleri görsel olarak işlenmiştir. Eksenel yük seviyesi, yatay ve düşey donatı oranı gibi, akma ve göçme öncesi eğrilik değerlerini etkileyen parametreler plastik dönme ve yönetmeliğin öngördüğü hasar sınırlarını etkilemektedir. Yatay donatı oranının artması ve aralığının azalması sonucunda perde duvar kesitleri daha güvenli yönde kalmaktadır.

\section{Deformation Based Damage Limits of the Ductile Reinforced Concrete Shear Walls}

\author{
${ }^{1}$ Konya Technical University, Faculty of Engineering and Natural Sciences, Department of Civil Engineering, Konya, Turkey
}

Article History

Received: $\quad 22.12 .2020$

Accepted: $\quad 06.05 .2021$

Published: $\quad 30.06 .2021$

Research Article

\begin{abstract}
Nonlinear behaviour and deformation-based damage limits investigated to determine the seismic performance of the shear walls. Ten high ductility levels shear walls having different parameters were designed and analysed. Deformation limits and plastic rotation limits of shear walls were calculated for the different performance level damage limits defined in Turkey Building Earthquake Code 2018. Effective section stiffness and yield rotation values were also calculated for the evaluation and design of shear walls according to deformation. According to Turkey Building Earthquake Code 2018, in the calculation of deformation limits for different performance levels of shear walls; material strengths, reinforcement configuration in the cross-section, the stress-strain relationship of the confined concrete used, nonlinear behaviour of the sections such as moment-curvature and plastic hinge properties are taken into consideration. The damage limits corresponding to the deformation demands according to different performance levels were obtained and evaluated for shear walls. Concrete strain values for different transverse reinforcement ratios, yield and plastic rotation values at different axial load levels were calculated and investigated for different performance levels. On the moment-curvature relationships obtained for shear walls, the damage limits and regions to be calculated according to the Turkey Building Earthquake Code 2018 were visually processed. Parameters such as axial load levels, transverse and longitudinal reinforcement ratios that affect the yield and ultimate curvature values, also affect the plastic rotation and the damage limits stipulated by the regulation. The shear wall sections remain in a safer direction as the transverse reinforcement ratio increases and the spacing decreases.
\end{abstract}

\footnotetext{
1 (D) saeid.foroughi@yahoo.com

2 (D) sbyuksel@ktun.edu.tr

*Sorumlu Yazar / Corresponding Author
} 


\section{Giriş}

Betonarme perde duvarların sismik davranışı, genel yapının sismik performansı üzerinde büyük bir etkiye sahiptir (Xiao-chun ve Xiao-lei, 2011). Şekildeğiştirme esaslı tasarım yöntemleri; malzemenin doğrusal olmayan davranışını dikkate almaktadır. Doğrusal olmayan hesap yöntemleriyle hesaplanan şekildeğiştirme sınır değerleri, deprem yönetmeliklerinde farklı performans düzeyleri için tanımlanan sınır değerler ile karşılaştırılarak taşıyıcı sistem elemanlarının hangi hasar bölgelerinde olduğuna karar verilir (Foroughi ve Yüksel, 2019).

Mevcut veya yeni yapılacak betonarme binaların kapsamlı bir performansa dayalı sismik değerlendirmesi için betonarme perde duvarların deformasyon kapasitesinin tahmin edilmesi çok önemlidir (Özdemir, Kazaz ve Özkaya, 2017). Yer değiştirme sünekliği, yapıların sismik tepkisini karakterize eden bir parametredir. Ayrıca, deplasman sünekliği, belirli sismik yönetmeliklere göre gerçekleştirilen bir yapısal tasarımda, sismik tasarımın ana amacına ulaşıp ulaşamayacağını belirlemek için kullanılabilir (Perez ve Mulder, 2018). Betonarme perde duvarlar, depreme dayanıklı bina tasarımında veya mevcut yapıların deprem açısından güçlendirilmesinde etkin olarak kullanılmaktadır. Deplasman esaslı yapılan sismik tasarımda ve yapısal elemanların performans değerlendirmesi için süneklik ve eğrilik gibi kesitsel deformasyon miktarları büyük önem taşımaktadır. Doğrusal olmayan analiz, yapısal elemanların deformasyon yanıtının yer değiştirme tabanlı prosedürlere göre tahmin edildiği yöntemlerdir (Kazaz, Gülkan ve Yakut, 2012a). Betonarme perde duvarlarda uç bölgeleri, eksenel yük oranı, perde duvar en boy oranı $\left(b_{w} / l_{w}\right)$ ve kesme açıklı̆̆ dâhil olmak üzere perde duvarların deformasyon kapasitesini etkileyen çeşitli faktörler vardır. Uç bölgeleri, betonarme perde duvarların hasar modunu ve deformasyon kapasitesini kontrol eden önemli parametrelerden biridir (Zhou, Zhang, Huang ve Li, 2014).

Qian ve Xu (2007), betonarme perde duvarlar için yer değiştirme tabanlı bir performans sınırı için tasarım yöntemi geliştirmiş ve belirli bir hasar talebine göre enine donatı için karakteristik bir bağıntı önermişlerdir. Xin, Liang ve Deng (2009) farklı sismik seviyelerde ve eksenel basınç oranlarında, perde duvar uç bölgesi uzunluğunu ve donatı detaylandırmasını incelemişlerdir. Hong, Lu, Yang ve Zhang (2008) perde duvar uç bölgesi hasar modu, taşıma kapasitesi, süneklik oranı, sertlik ve betonarme perdelerin enerji yayma kapasitesi üzerindeki etkisini tartışmışlardır. Wallace ve Moehle (1992) geliştirdikleri yöntemle perdelerin şekil değiştirme talebi ile kapasiteyi karşılaştırarak perde uç bölgelerinde gerekli olan donatı detaylandırması ve sünekliği araştırmıştır. Deprem performans ve güçlendirilmesi için alternatif yaklaşım şekil değiştirme esaslı tasarımdır. Şekil değiştirme esaslı tasarımın yeni binalarda uygulanması deprem mühendisliğinde son yıllarda oldukça ilgi gören bir alandır (Karageyik ve Sucuoğlu, 2011; Moehle, 1992; Panagiotakos ve Fardis, 1999; Priestley, Calvi, Kowalsky ve Powell, 2008; Tjhin, Ascheim ve Wallace, 2007). Perde duvarlı binalarda, limit durumları ve karşılık gelen sınır değerleri tanımlamak için betonarme yapısal duvarların deformasyon sınırlarının araştırılması gerekmektedir (Taleb, 2018). Betonarme elemanlarda performansın ve hasarın doğru analitik değerlendirilmesi için, belirli hasar durumlarında iyi tanımlanmış deformasyon limitleri gereklidir (Kazaz, Gülkan ve Yakut, 2012b).

Gerçek yapısal davranışın daha doğru bir simülasyonunu elde etmek için, betonarme elemanların doğru moment-eğrilik ilişkileri ile sargısız ve sargılı betonun gerilme-şekil değiştirme ilişkilerinin incelenmesi gerekmektedir (Foroughi ve Yüksel, 2020a). Daha önceki çalışmalarda, betonarme taşıyıcı elemanların moment-eğrilik, yanal kuvvet-tepe deplasman, eğrilik sünekliği ile deplasman süneklik davranışlarının, eksenel yük, boyuna ve enine donatı oranlarında meydana gelen değişikliklerden önemli ölçüde etkilendiği gözlenmiştir (Foroughi ve Yüksel, 2020b, 2020c). Betonarme perde duvarların yük taşıma kapasiteleri ile şekil değiştirmeyi inceleyen önceki çalışmalara bakıldı̆̆ında (Rutenberg ve Nsieri, 2006) perde davranışını etkileyen en önemli değişkenlerin perde duvarların yükseklik / plandaki uzunluk oranı $\left(H_{w} / l_{w}\right)$, eksenel yük oranı $\left(N / N_{\max }\right)$, boyuna ve yatay donatı oranı olduğu sonucu elde edilmiştir.

Süneklik düzeyi yüksek betonarme perde duvarların kesit tasarımı, geometrisi, boyuna donatı oranı, yatay donatı oranı ve yerleşimleri Betonarme Yapıların Tasarım ve Yapım Kuralları (TS500, 2000) ve Türkiye Bina Deprem Yönetmeliğinde (TBDY, 2018) verilen hükümler dikkate alınarak tasarlanmıştır (bkz. Şekil 1). Tasarlanan perde duvarların planda uzun kenarının $\left(l_{w}\right)$ kalınlığına $\left(b_{w}\right)$ oranı 6'dan büyük olarak belirlenmiştir. Farklı boyuna ve yatay donatı oranına sahip tasarlanan süneklik düzeyi yüksek betonarme perde 
duvarların davranışları, malzemelerin doğrusal olmayan davranışı dikkate alınarak gerilme-şekil değiştirme ve moment-eğrilik ilişkilerinden incelenmiştir. Deprem etkisi altında binaların şekil değiştirmeye göre değerlendirmesi için betonarme perde duvarların etkin kesit rijitliği, etkin rijitlik katsayısı, akma dönmesi ve süneklik değerleri TBDY (2018)'de verilen bağıntılar ve kesitlerin moment-eğrilik ilişkilerinden elde edilen değerlere göre hesaplanmıştır. Betonarme perde duvarlar için TBDY (2018)'de tanımlanan Göçme Öncesi (GÖ), Kontrollü Hasar (KH) ve Sınırlı Hasar ( $\mathrm{SH}$ ) performans düzeyleri için oluşan şekil değiştirme sınırları, farklı yatay donatı oranına göre beton birim şekil değiştirmeleri ve farklı eksenel yük seviyelerde plastik dönmeler hesaplanarak performans düzeyleri araştırılmıştır. Doğrusal olmayan hesap yöntemleriyle elde edilen şekil değiştirme sınır değerleri, perde duvar hasar sınırlarına karşı gelmek üzere TBDY (2018)'de öngörülen sayısal değerler ile karşılaştırarak performans düzeyleri hesaplanmıştır.

\section{Betonarme Bina Elemanlarının Birim Şekil Değiştirme Sınırları}

TBDY (2018)'de yapılacak performans değerlendirmesinde yapısal betonarme taşıyıcı elemanlar için GÖ, $\mathrm{KH}$ ve SH performans düzeyi ve sınır değerleri tanımlanmıştır. Betonarme kesitlerde SH performans düzeyi için sınırlı miktarda, KH için dayanımının güvenli olarak sağlanabileceği ve GÖ ise ileri düzeyde doğrusal olmayan davranışı tanımlamaktadır. Farklı performans düzeyleri için yayılı plastik davranış modeline göre donatı çeliği ile beton birim şekil değiştirme sınır değerleri Tablo 1'de verilmiştir. Performans düzeyleri için yığılı plastik davranış modeline göre plastik dönme sınır değerleri Tablo 2'de verilmiştir. Taşıyıcı elemanlarda eksenel yük seviyesi ve malzeme modelleri dikkate alınarak moment-eğrilik ilişkilerinden plastik dönme değerleri hesaplanabilmektedir.

Tablo 1

Performans düzeylerine göre şekil değiştirme sınırları (TBDY, 2018)

\begin{tabular}{l|ll}
\hline \multicolumn{1}{c|}{$\begin{array}{c}\text { Şekil değiştirme } \\
\text { sinırları }\end{array}$} & \multicolumn{1}{|c}{$\begin{array}{c}\text { Betonda birim } \\
\text { kısalma }\end{array}$} & \multicolumn{1}{c}{$\begin{array}{c}\text { Donatıda birim } \\
\text { şekil değiştirme }\end{array}$} \\
\hline $\mathrm{GOO}$ & $\varepsilon_{\mathrm{c}}^{(\mathrm{GÖ})}=0.0035+0.04 \sqrt{\omega_{\mathrm{we}}} \leq 0.018$ & $\varepsilon_{\mathrm{s}}^{(\mathrm{GÖ})}=0.40 \varepsilon_{\mathrm{su}}$ \\
$\mathrm{KH}$ & $\varepsilon_{\mathrm{c}}^{(\mathrm{KH})}=0.75 \varepsilon_{\mathrm{c}}^{(\mathrm{GÖ})}$ & $\varepsilon_{\mathrm{s}}^{(\mathrm{KH})}=0.75 \varepsilon_{\mathrm{s}}^{(\mathrm{GÖ})}$ \\
$\mathrm{SH}$ & $\varepsilon_{\mathrm{c}}^{(\mathrm{SH})}=0.0025$ & $\varepsilon_{\mathrm{s}}^{\mathrm{SH})}=0.0075$ \\
\hline
\end{tabular}

Tablo 2

Performans düzeylerine göre plastik dönme sınırları (TBDY, 2018)

\begin{tabular}{l|l}
\hline Şekil değiştirme sınırları & \multicolumn{1}{|c}{ Plastik dönmeler } \\
\hline GÖ & $\theta_{\mathrm{p}}^{(\mathrm{GÖ})}=\frac{2}{3}\left[\left(\emptyset_{\mathrm{u}}-\emptyset_{\mathrm{y}}\right) \mathrm{L}_{\mathrm{p}}\left(1-0.5 \frac{\mathrm{L}_{\mathrm{p}}}{\mathrm{L}_{\mathrm{s}}}\right)+4.5 \emptyset_{\mathrm{u}} \mathrm{d}_{\mathrm{b}}\right]$ \\
$\mathrm{KH}$ & $\theta_{\mathrm{p}}^{(\mathrm{KH})}=0.75 \theta_{\mathrm{p}}^{(\mathrm{GÖ})}$ \\
$\mathrm{SH}$ & $\theta_{\mathrm{p}}^{(\mathrm{SH})}=0$ \\
\hline
\end{tabular}

$\omega_{w e}$, etkin yatay donatısının mekanik donatı oranı Denklem (2.1) ile hesaplanabilmektedir. Yatay donatısının etkinlik katsayısı $\left(\alpha_{s e}\right)$ ve minimum hacimsel yatay donatı oranı $\left(\rho_{s h}\right)$ Denklem (2.2) ile hesaplanmaktadır. $f_{y w e}$ ve $f_{c e}$ donatı çeliği ve beton için beklenen dayanımıdır $\left(f_{c e}=1.3 f_{c k}, f_{y e}=1.2 f_{y k}\right)$. $A_{s h}$ ve $s$ yatay donatı alanı ve aralığıdır. $b_{o}$ ve $h_{o}$; yatay donatı arasında kalan sargılı beton boyutu ve $a_{i}$; bir yatay donatı veya çiroz tarafindan mesnetlenen boyuna donatıların eksenleri arasındaki mesafedir.

$$
\begin{aligned}
& \omega_{w e}=\alpha_{s e} \rho_{s h, \min } \frac{f_{y w e}}{f_{c e}} \\
& \alpha_{s e}=\left(1-\frac{\sum a_{i}^{2}}{6 b_{o} h_{o}}\right)\left(1-\frac{s}{2 b_{o}}\right)\left(1-\frac{s}{2 h_{o}}\right), \quad \rho_{s h}=\frac{A_{s h}}{b_{k} s}
\end{aligned}
$$


Betonarme perde modellerinin analizlerinde sargısız ve sargılı beton modelleri için Mander, Priestley ve Park (1988) tarafindan geliştirilen model kullanılmıştır. Mander modeline göre sargı etki katsayısı $\left(k_{e}\right)$ Denklem (2.3), $x$ ve $y$ yönünde çekirdek betona uygulanan etkili yanal basınçlar ve ortalama basınç dayanımı $\left(f_{l x}^{\prime}\right.$ ve $f_{l y}^{\prime}$ ) Denklem (2.4a) ve (2.4b), sargılı beton basınç dayanımı $\left(f_{c c}^{\prime}\right)$ Denklem (2.5) ve maksimum basınç gerilmesine karşı gelen birim şekildeğiştirme değerleri $\left(\varepsilon_{c c}\right)$ Denklem (2.6) ile hesaplanmaktadır. Betondaki en büyük birim şekildeğiştirme değeri $\varepsilon_{c u}$ enine donatıda oluşan ilk kopma anındaki değere karşılık gelir. Sargılı betondaki maksimum basınç birim şekildeğiştirmesi $\varepsilon_{c u}$ Denklemden (2.7) hesaplanabilmektedir.

$$
\begin{aligned}
& k_{e}=\left(1-\sum_{i}^{n} \frac{\left(w_{i}^{\prime}\right)^{2}}{6}\right)\left(1-\frac{S^{\prime}}{2 b_{c}}\right)\left(1-\frac{S^{\prime}}{2 d_{c}}\right) /\left(1-\rho_{c c}\right) \\
& f_{l x}^{\prime}=k_{e} \frac{A_{s x}}{s d_{c}} f_{y h}=k_{e} f_{l x} \\
& f_{l y}^{\prime}=k_{e} \frac{A_{s y}}{s b_{c}} f_{y h}=k_{e} f_{l y} \\
& f_{c c}^{\prime}=f_{c o}^{\prime}\left(-1.254+2.254 \sqrt{\left.1+\frac{7.94 f_{l}^{\prime}}{f_{c o}^{\prime}}-2 \frac{f_{l}^{\prime}}{f_{c o}^{\prime}}\right)}\right. \\
& \varepsilon_{c c}=\varepsilon_{c o}\left[1+5\left(\frac{f_{c c}^{\prime}}{f_{c o}^{\prime}}-1\right)\right] \\
& \varepsilon_{c u}=0.004+\frac{1.4 \rho_{s} f_{y w} \varepsilon_{s u}}{f_{c c}^{\prime}}
\end{aligned}
$$

\section{Betonarme Elemanlarının Etkin Kesit Rijitlikleri}

Çatlamış kesite ait etkin kesit rijitlikleri $\left(E I_{e}\right)$, moment-eğrilik ilişkisi dikkate alınarak, akma momentinin akma eğriliğine oranı olarak $\left(M_{y} / \emptyset_{y}\right)$ hesaplanır. $E I_{e}$ sabit olmamakla birlikte; beton basınç dayanımı, kesit geometrisi, kesit boyutu ve kesite etkiyen eksenel yük seviyesi gibi tasarım parametrelerine bağlıdır. Betonarme perdelerin brüt atalet momenti $(I)$ ve betonun elastisite modülüne $\left(E_{c}=3250+\sqrt{f_{c k}}+14000\right)$ göre çatlamamış kesit rijitlikleri $(E I)$ hesaplanmıştır. Betonarme taşıyıcı elemanların etkin kesit rijitlikleri moment-eğrilik ilişkilerinden, $k_{e}=E I_{e} / E I$ olarak hesaplanmaktadır. Doğrusal olmayan hesap için taşıyıcı sistemlerin akma durumu için yer değiştirmiş plastik mafsal akma dönmesi $\left(\theta_{y}\right)$ Denklem (3.1) ile hesaplanmıştır. Yığılı plastik davranışına göre modellenen perdelerin etkin kesit rijitlikleri Denklem (3.2)'e göre belirlenmiştir. Denklemde; $L_{s}$ kesme açıklığı ve perde duvarlar için $\eta=0.50$ olarak alınmıştır. Süneklik katsayısı, moment-eğrilik analizlerinden hesaplanan göçme öncesi eğriliğin akma eğriliğine oranı olarak hesaplanir $\left(\mu=\emptyset_{u} / \emptyset_{y}\right)$.

$$
\begin{aligned}
& \theta_{y}=\frac{\emptyset_{y} L_{s}}{3}+0.0015 \eta\left(1+1.5 \frac{h}{L_{S}}\right)+\frac{\emptyset_{y} d_{b} f_{y e}}{8 \sqrt{f_{c e}}} \\
& (E I)_{e}=\frac{M_{y}}{\theta_{y}} \frac{L_{s}}{3}
\end{aligned}
$$

\section{Materyal ve Yöntem}

$\mathrm{Bu}$ çalışmada betonarme yapısal elemanların şekildeğiştirme esaslı hasar sınırlarının belirlenmesi için farklı parametrelere sahip süneklik düzeyi yüksek betonarme perde duvar modelleri tasarlanmıştır. Perde duvarın kalınlığ $b_{w}=300 \mathrm{~mm}$, plandaki uzunluğu $l_{w}=3000 \mathrm{~mm}$ ve uç bölgelerinin her birinin plandaki uzunluğu $l_{u}=600 \mathrm{~mm}$ olarak belirlenmiştir $\left(l_{u} \geq 2 b_{w}\right.$ ve $\left.l_{u} \geq 0.2 l_{w}\right)$. Tasarlanan betonarme perde duvarların görünüşü Şekil 1'de ve perde duvar modellerine ait parametreler ve detaylar Tablo 3'te 
verilmiştir. Betonarme perde duvarın uç bölgelerindeki düşey ve yatay donatı oranları TBDY (2018)'de verilen kurallara göre belirlenmiştir. TBDY (2018)'e göre tasarlanan betonarme perde duvar için uç ve gövde bölgelerindeki donatıların sınırlamaları kontrol edilmiştir. Tasarlanan betonarme perde duvar için uç ve gövde bölgelerindeki düşey donatı sınırlamalarının kontrolü Tablo 4'te verilmiştir. Tüm modeller için, C30 beton sınıfı ve B420C donatı çeliği dikkate alınmıştır. Yapılan analitik çalışmada TBDY (2018)'de donatı çeliği ve beton için verilen malzeme özellikleri dikkate alınmıştır.

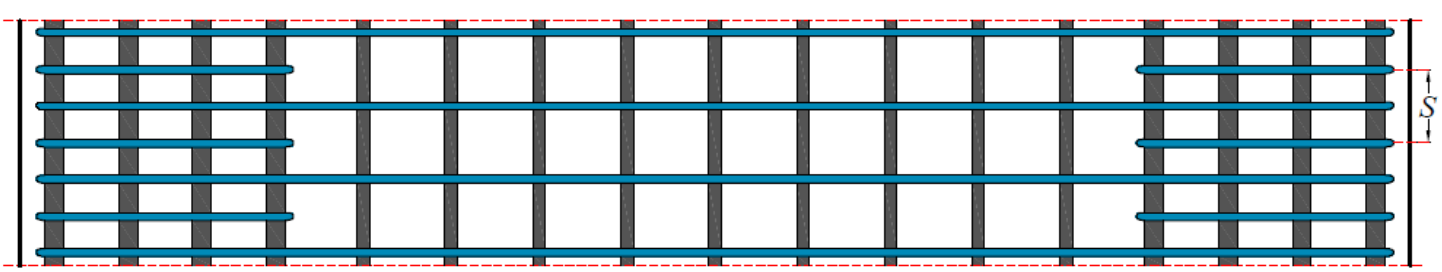

A-A Kesiti

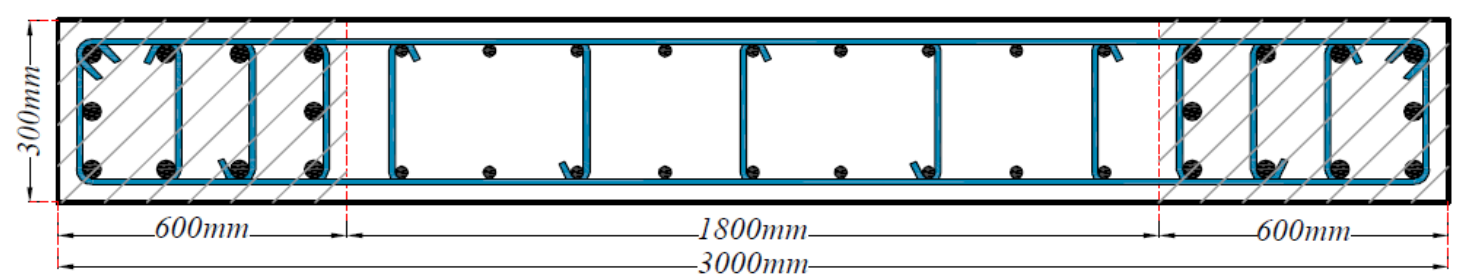

Şekil 1. Betonarme perde duvar modellerinin kesiti

Tablo 3

Tasarlanan betonarme perde duvar modellerine ait detaylar

\begin{tabular}{l|cccc}
\hline \multirow{2}{*}{ Kesit No } & \multicolumn{3}{|c}{ Perde duvar uç bölgesi } & \multicolumn{2}{c}{ Perde duvar gövde bölgesi } \\
\cline { 2 - 5 } & Düşey donatı $(\mathrm{mm})$ & Yatay donatı $(\mathrm{mm})$ & Düşey donatı $(\mathrm{mm})$ & Yatay donatı $(\mathrm{mm})$ \\
\hline P1 & & $\Phi 8 / 150$ & & $\Phi 8 / 150$ \\
P2 & $10 \Phi 16$ & $\Phi 8 / 100$ & $18 \Phi 12$ & $\Phi 8 / 100$ \\
P3 & & $\Phi 8 / 50$ & & $\Phi 8 / 50$ \\
P4 & & $\Phi 10 / 100$ & $\Phi 10 / 100$ \\
P5 & $10 \Phi 16$ & $\Phi 12 / 100$ & $18 \Phi 12$ & $\Phi 12 / 100$ \\
P6 & & $\Phi 14 / 100$ & & $\Phi 14 / 100$ \\
P7 & $10 \Phi 18$ & $\Phi 12 / 100$ & $18 \Phi 12$ & $\Phi 12 / 100$ \\
P8 & $10 \Phi 20$ & & $18 \Phi 14$ & \\
P9 & $10 \Phi 20$ & $\Phi 12 / 100$ & $18 \Phi 16$ & $\Phi 12 / 100$ \\
P10 & & & & \\
\hline
\end{tabular}

Tasarlanan betonarme perde modellerinin gerilme-şekil değiştirme ve moment-eğrilik ilişkileri elde edilmiş, gerekli hesaplar ve incelemeler yapılmıştır. Farklı eksenel yük, boyuna ve yatay donatı oranları için analizlerden elde edilen gerilme-şekil değiştirme ve moment-eğrilik ilişkileri karşışş̧ırmalı olarak sunulmuştur. Betonarme perde duvarlarda malzemelerin doğrusal olmayan davranışı dikkate alınarak farklı tasarım parametreler için moment-eğrilik analizler SAP2000 (SAP2000, v.20.2.0) programı ile yapılmıştır. Kombine bükülme altındaki bir kesitin moment-eğrilik ilişkileri, eksenel yük seviyelerine bağlıdır. Düşey yükler ve deprem yüklerinin ortak etkisi altında hesaplanan eksenel basınç kuvvetlerinin en büyüğü olmak üzere, $A_{c} \geq N_{d m} / 0.35 f_{c k}$ koşulu sağlanmalıdır (TBDY, 2018). Betonarme perde duvar kesitlerinde, $N_{\max }=$ $A_{c} \times f_{c k}$ olmak üzere $N / N_{\max }$ oranının $0.15,0.25$ ve 0.35 değerleri için moment-eğrilik analizleri yapılmıştır. Moment-eğrilik ilişkilerinden akma ve kırılma durumları için moment $\left(M_{y}, M_{u}\right)$ ve eğrilik $\left(\emptyset_{y}, \emptyset_{u}\right)$ değerleri, akma ve kırılma eğriliklerinden eğrilik süneklikleri $(\mu)$, etkin eğilme rijitlikleri $\left(E I_{e}\right)$ ve etkin rijitlik katsayısı $\left(k_{e}\right)$ hesaplanmıştır. GÖ, KH ve SH performans düzeyleri için oluşan sınır değerleri, farklı düşey ve yatay 
donatı oranına göre hesaplanan donatı çeliği ve beton birim şekildeğiştirmeleri, farklı eksenel yük oranına göre moment-eğrilik analizlerinden hesaplanan akma ve göçme öncesi eğrilik değerleri, plastik mafsal uzunluğu, kesme uzunluğu ve düşey donatı çapına göre kesitlerin plastik dönmeleri hesaplanarak farklı parametrelere göre karşılaştırılmıştır. Betonarme perde duvarlarda plastik mafsal uzunluğunu hesaplamak için birçok farklı ampirik denklemler önerilmiştir. Plastik mafsal uzunluğu, eğrilik kapasitesinden güvenli bir yer değiştirme kapasitesini elde etmek için perde duvar uzunluğunun yarısı olarak kabul edilebilir (Bohl ve Adebar, 2011). Betonarme perde duvarlarda plastik mafsal uzunluğu; $L_{p}=0.5 L_{w}=1.5 \mathrm{~m}$ ve kesme uzunluğu $L_{s}=3 \mathrm{~m}$ olarak alınmıştır.

Tablo 4

Tasarlanan perde duvarlar için gövde ve uç bölgelerinde düşey donatı sınırlamaları

Perde gövde bölgelerinde düşey donatı kontrolü

\begin{tabular}{l|ccc}
\hline $\begin{array}{c}\text { Seçilen gövde düşey donatıs1 } \\
\mathrm{A}_{\mathrm{s}}\end{array}$ & $18 \Phi 12$ & $18 \Phi 14$ & $18 \Phi 16$ \\
$\frac{\mathrm{L}}{\left(\mathrm{L}_{\mathrm{w}}-2 \mathrm{l}_{\mathrm{u}}\right) \times \mathrm{b}_{\mathrm{w}}} \geq 0.0025$ & $0.0038 \geq 0.0025$ & $0.0051 \geq 0.0025$ & $0.0067 \geq 0.0025$ \\
\hline \multicolumn{4}{c}{ Perde uç bölgelerinde düşey donatı kontrolü } \\
\hline $\begin{array}{l}\text { Seçilen uç bölge düşey donatısı } \\
\frac{\mathrm{A}_{\mathrm{s}}}{\mathrm{L}_{\mathrm{w}} \times \mathrm{b}_{\mathrm{w}}} \geq 0.002\end{array}$ & $10 \Phi 16$ & $10 \Phi 18$ & $10 \Phi 20$ \\
\hline
\end{tabular}

\section{Araştırma Bulguları ve Tartışma}

Tasarlanan betonarme perde duvarların farklı tasarım parametrelerine göre sargılı basınç dayanımı hesaplanmış (bkz. Şekil 2) ve elde edilen sonuçlar farklı tasarım parametrelerine göre karşılaştırılmıştır. Betonarme perde duvarların moment-eğrilik analizlerinden elde edilen sonuçlar kullanılarak kesitlerin $\emptyset_{y}, M_{y}$, $\emptyset_{u}$ ve $M_{u}$ değerleri farklı eksenel yük seviyelerine göre Tablo 5'te verilmiştir. Analiz sonuçlarından elde edilen moment-eğrilik ilişkileri Şekil 3 'te sunulmuştur. Tablolarda $M_{y}$ ve $M_{u}$ değerleri; $(k N . m), \emptyset_{y}$ ve $\emptyset_{u}$ değerleri; $(\mathrm{Rad} / \mathrm{m}),(E I)_{e}$ değerleri; $\left(k N . \mathrm{m}^{2}\right)$ ve $\theta_{y}$ değerleri; $(\mathrm{Rad})$ olarak verilmiştir.
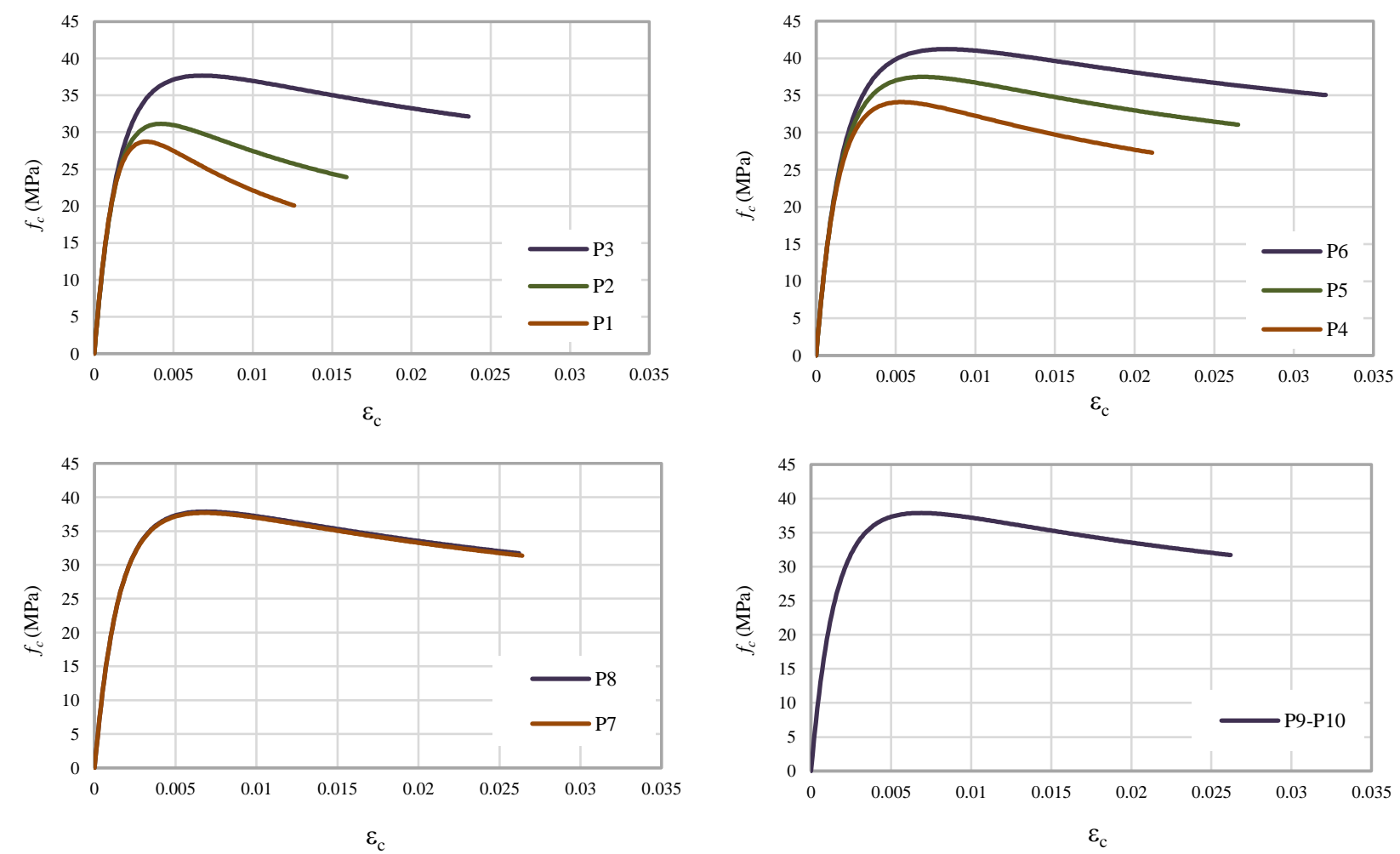

Şekil 2. Perde duvarların uç bölgelerinin gerilme-şekil değiştirme ilişkileri 
Tablo 5

Perde duvarların akma ve kırılma durumu için hesaplanan M ve $\emptyset$ değerleri

\begin{tabular}{l|lcccccccccc}
\hline$N_{d}$ & $M, \varnothing$ & $\mathrm{P} 1$ & $\mathrm{P} 2$ & $\mathrm{P} 3$ & $\mathrm{P} 4$ & $\mathrm{P} 5$ & $\mathrm{P} 6$ & $\mathrm{P} 7$ & $\mathrm{P} 8$ & $\mathrm{P} 9$ & $\mathrm{P} 10$ \\
\hline \multirow{5}{*}{0.15} & $\mathrm{M}_{\mathrm{y}}$ & 6847 & 6867 & 6895 & 6835 & 6897 & 6926 & 7328 & 7811 & 7899 & 7986 \\
& $\emptyset_{\mathrm{y}}$ & 0.0012 & 0.0012 & 0.0012 & 0.0012 & 0.0012 & 0.0012 & 0.0012 & 0.0012 & 0.0012 & 0.0012 \\
& $\mathrm{M}_{\mathrm{u}}$ & 7823 & 7941 & 8506 & 8187 & 8471 & 8672 & 9144 & 9891 & 10180 & 10500 \\
& $\emptyset_{\mathrm{u}}$ & 0.0187 & 0.0246 & 0.0412 & 0.0352 & 0.0414 & 0.0428 & 0.0413 & 0.0413 & 0.042 & 0.0431 \\
\hline \multirow{5}{*}{0.25} & $\mathrm{M}_{\mathrm{y}}$ & 8841 & 8871 & 8964 & 8896 & 8971 & 9043 & 9403 & 9896 & 9955 & 10026 \\
& $\emptyset_{\mathrm{y}}$ & 0.0013 & 0.0013 & 0.0013 & 0.0013 & 0.0013 & 0.0013 & 0.0013 & 0.0013 & 0.0013 & 0.0013 \\
& $\mathrm{M}_{\mathrm{u}}$ & 9704 & 9837 & 10236 & 9946 & 10169 & 10610 & 10798 & 11503 & 11688 & 11892 \\
& $\emptyset_{\mathrm{u}}$ & 0.0118 & 0.0172 & 0.0286 & 0.0244 & 0.0329 & 0.0406 & 0.0311 & 0.0314 & 0.0293 & 0.0292 \\
\hline \multirow{5}{*}{0.35} & $\mathrm{M}_{\mathrm{y}}$ & 10290 & 10379 & 10546 & 10449 & 10531 & 10671 & 10972 & 11464 & 11514 & 11570 \\
& $\emptyset_{\mathrm{y}}$ & 0.0016 & 0.0015 & 0.0015 & 0.0015 & 0.0015 & 0.0015 & 0.0015 & 0.0015 & 0.0015 & 0.0015 \\
& $\mathrm{M}_{\mathrm{u}}$ & 9999 & 11028 & 11519 & 11223 & 11487 & 11756 & 12011 & 12595 & 12715 & 12848 \\
& $\emptyset_{\mathrm{u}}$ & 0.0091 & 0.0118 & 0.0209 & 0.0175 & 0.0244 & 0.0291 & 0.0244 & 0.0244 & 0.0244 & 0.0243 \\
\hline
\end{tabular}

Doğrusal olmayan hesap için betonarme perde duvarların etkin kesit rijitliği, etkin rijitlik katsayısı, akma dönmesi ve süneklik değerleri elde edilmiştir. Araştırılan parametreler TBDY (2018)'de verilen bağıntılar ve perde duvarların moment eğrilik analizlerinden hesaplanmıştır.

Betonarme perde duvarları için moment-eğrilik ilişkilerinden elde edilen $\mu-N / N_{\max }$ ve $k_{e}-N / N_{\max }$ ilişkileri Şekil 4 ve Şekil 5 'te karşılaştırılmıştır. Betonarme perde duvarların plastik mafsal akma dönmesi $\left(\theta_{y}\right)$ değerleri farklı eksenel yük değerlerine göre Tablo 6'da özetlenmiştir. Betonarme taşııcı sistemlerinin etkin kesit rijitliklerinin hesaplanmasında, gerçekçi yollardan birisi de moment-eğrilik ilişkilerinin kullanılmasıdır. Betonarme kesitlerde $E I_{e}$ değerleri, moment-eğrilik eğrilik ilişkisi ve yığılı plastik davranışına göre Denklem (3.2)'den hesaplanmıştır (bkz. Tablo 7). Betonarme perde duvarların farklı tasarım parametrelerine göre $N /$ $N_{\max }-\theta_{p}$ ilişkileri Şekil 6'da verilmiştir. Farklı performans düzeyi için $\varepsilon_{s}^{(G O ̈)}=0.032, \varepsilon_{s}^{(K H)}=0.024$ ve $\varepsilon_{S}^{(S H)}=0.0075$ sabit değerler olarak hesaplanmaktadır. Betonarme perde duvarlar için hesaplanan hasar sınırları $\left(\varepsilon_{c}^{(K H)}, \varepsilon_{c}^{(G O ̈)}\right)$ ve bölgeleri üzerine işlenmiş moment-eğrilik ilişkileri sırasıyla Şekil 7, 8, 9 ve 10'da verilmiştir.

Betonarme perde duvarların uç bölgelerindeki boyuna donatı oranının artması $f_{c c}^{\prime}, \varepsilon_{c c}$ ve $\varepsilon_{c u}$ değerlerini çok fazla etkilememiştir. Perde duvarların uç bölgelerinde yatay donatı oranının artması ile $f_{c c}^{\prime}$, $\varepsilon_{c c}$ ve $\varepsilon_{c u}$ değerleri artmaktadır. Moment-eğrilik ilişkilerine göre; eksenel yük seviyesinin artmasıyla betonarme perde duvarların $M_{y}, \emptyset_{y}$ ve $M_{u}$ değerleri artmakta $\emptyset_{u}$ ve $\mu$ değerleri azalmaktadır. Perde duvarlarda yatay donatı oranının artmasıyla $M_{y}, M_{u}$ ve $\emptyset_{u}$ değerleri artarken $\emptyset_{y}$ değerleri sabit kalmaktadır. Perde duvarlarda uç ve gövde bölgelerinde boyuna donatı oranının artmasıyla $M_{y}$ ve $M_{u}$ değerleri artmakta $\emptyset_{y}$ ve $\emptyset_{u}$ değerleri değişmemektedir. $N / N_{\max }$ değerinin artmasının eleman sünekliğini önemli derecede azalttığ görülmüştür.

Doğrusal olmayan davranışa göre hesaplanan $\theta_{y}$ değerleri, $N / N_{\max }$ değeri, perde duvar uç ve gövde bölgesinde boyuna ve yatay donatı oranının artmasıyla artmaktadır. Perde duvar uç ve gövde bölgesinde boyuna ve yatay donatı oranının artmasıyla $E I_{e}$ artmaktadır. Hesaplanan $k_{e}$; uç ve gövde bölgesi boyuna ve yatay donatı oranının artmasıyla artmaktadır. $N / N_{\max }$ değerinin artmasına bağlı olarak $E I_{e}$ artmıştır.

$\varepsilon_{c}^{(G O ̈)}, \varepsilon_{c}^{(K H)}$ hasar sınırları $f_{y e}, f_{c e}$ ve yatay donatısının konfigürasyonuna bağlı olarak hesaplanmaktadır. Farklı performans düzeylerinde $\theta_{p}$ için izin verilen sınır değerleri; $\emptyset_{y}, \emptyset_{u}, L_{p}, L_{s}$ ve $d_{b}$ 'nin fonksiyonudur. Dolaysıyla kesit geometrisi, boyuna ve yatay donatı oranı, eksenel yük seviyesi ve yatay donatı konfigürasyonu gibi $\emptyset_{y}$ ve $\emptyset_{u}$ değerlerini etkiyen tasarım parametreleri $\theta_{p}$ sınır değerlerini de etkilemektedir. 

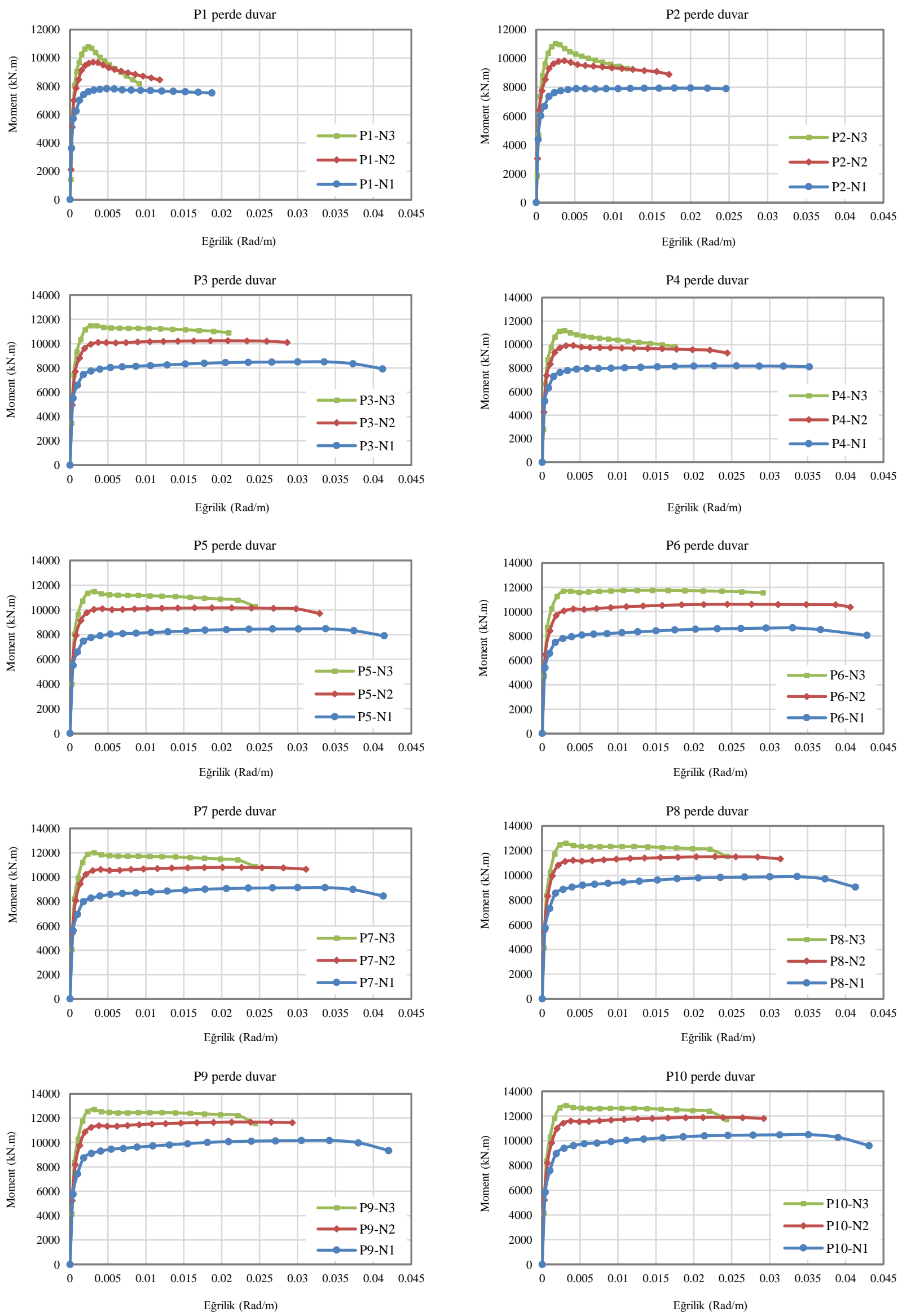

Şekil 3. Betonarme perde duvarlarının moment-eğrilik ilişkileri 

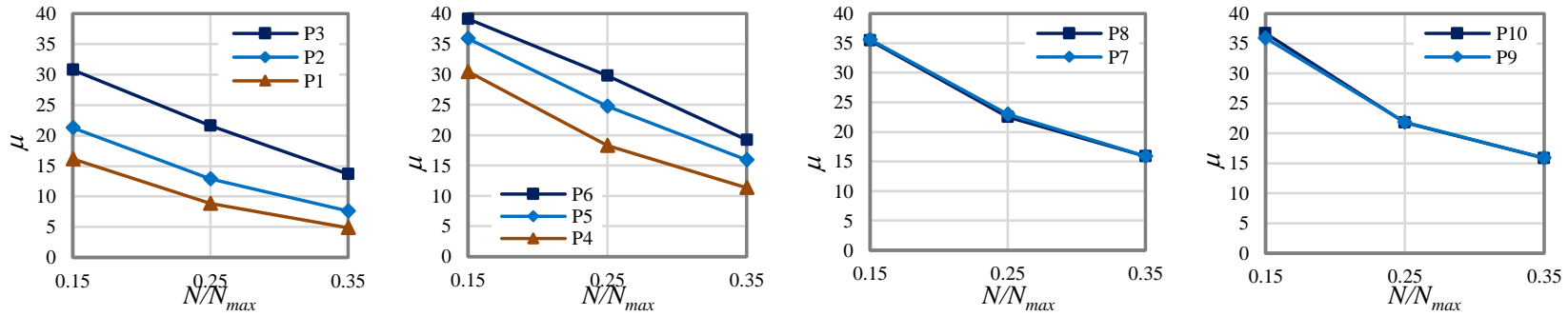

Şekil 4. Betonarme perde duvarlarının $\mu-N / N_{\max }$ ilişkileri
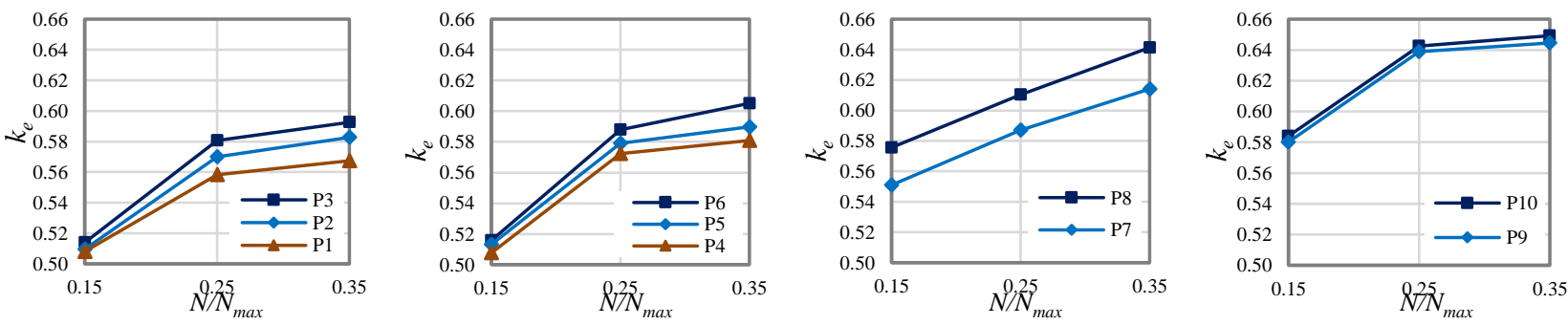

Şekil 5. Betonarme perde duvarlarının $k_{e}-N / N_{\max }$ ilişkileri

Tablo 6

Perde duvarların farklı eksenel yük seviyelerine göre hesaplanan $\theta_{y}$ değerleri

\begin{tabular}{l|cccccccccc}
\hline$N_{d}$ & P1 & P2 & P3 & P4 & P5 & P6 & P7 & P8 & P9 & P10 \\
\hline 0.15 & 0.00431 & 0.00431 & 0.00431 & 0.00431 & 0.00431 & 0.00431 & 0.00432 & 0.00432 & 0.00433 & 0.00433 \\
0.25 & 0.00452 & 0.00452 & 0.00451 & 0.00452 & 0.00451 & 0.00450 & 0.00452 & 0.00452 & 0.00452 & 0.00452 \\
0.35 & 0.00477 & 0.00476 & 0.00474 & 0.00475 & 0.00474 & 0.00472 & 0.00474 & 0.00474 & 0.00474 & 0.00474 \\
\hline
\end{tabular}

Tablo 7

Perde duvarların farklı eksenel yük seviyelerine göre hesaplanan $(E I)_{e}$ değerleri

\begin{tabular}{l|lcccccccccc}
\hline$N_{d}$ & $(E I)_{e}$ & $\mathrm{P} 1$ & $\mathrm{P} 2$ & $\mathrm{P} 3$ & $\mathrm{P} 4$ & $\mathrm{P} 5$ & $\mathrm{P} 6$ & $\mathrm{P} 7$ & $\mathrm{P}$ & $\mathrm{P} 9$ & $\mathrm{P} 10$ \\
\hline \multirow{2}{*}{0.15} & $\mathrm{M}_{\mathrm{y}} / \emptyset_{\mathrm{y}}$ & 5917891 & 5935177 & 5985763 & 5912630 & 5976603 & 6006938 & 6319966 & 6704721 & 6757057 & 6802385 \\
& Denk. 3.2 & 1588631 & 1593271 & 1599768 & 1585847 & 1600232 & 1606961 & 1696296 & 1808102 & 1824249 & 1844342 \\
\hline \multirow{2}{*}{0.25} & $\mathrm{M}_{\mathrm{y}} / \emptyset_{\mathrm{y}}$ & 6619001 & 6639970 & 6762221 & 6666167 & 6745113 & 6848682 & 6953853 & 7109195 & 7440765 & 7482648 \\
& Denk. 3.2 & 1955973 & 1962611 & 1987583 & 1968142 & 1989135 & 2009556 & 2080310 & 2189381 & 2202434 & 2218142 \\
\hline \multirow{2}{*}{0.35} & $\mathrm{M}_{\mathrm{y}} / \emptyset_{\mathrm{y}}$ & 6608863 & 6700452 & 6901832 & 6766172 & 6869537 & 7048217 & 7152542 & 7469377 & 7506846 & 7562092 \\
& Denk. 3.2 & 2157233 & 2180462 & 2224895 & 2199789 & 2221730 & 2260805 & 2314768 & 2418565 & 2429114 & 2440928 \\
\hline
\end{tabular}
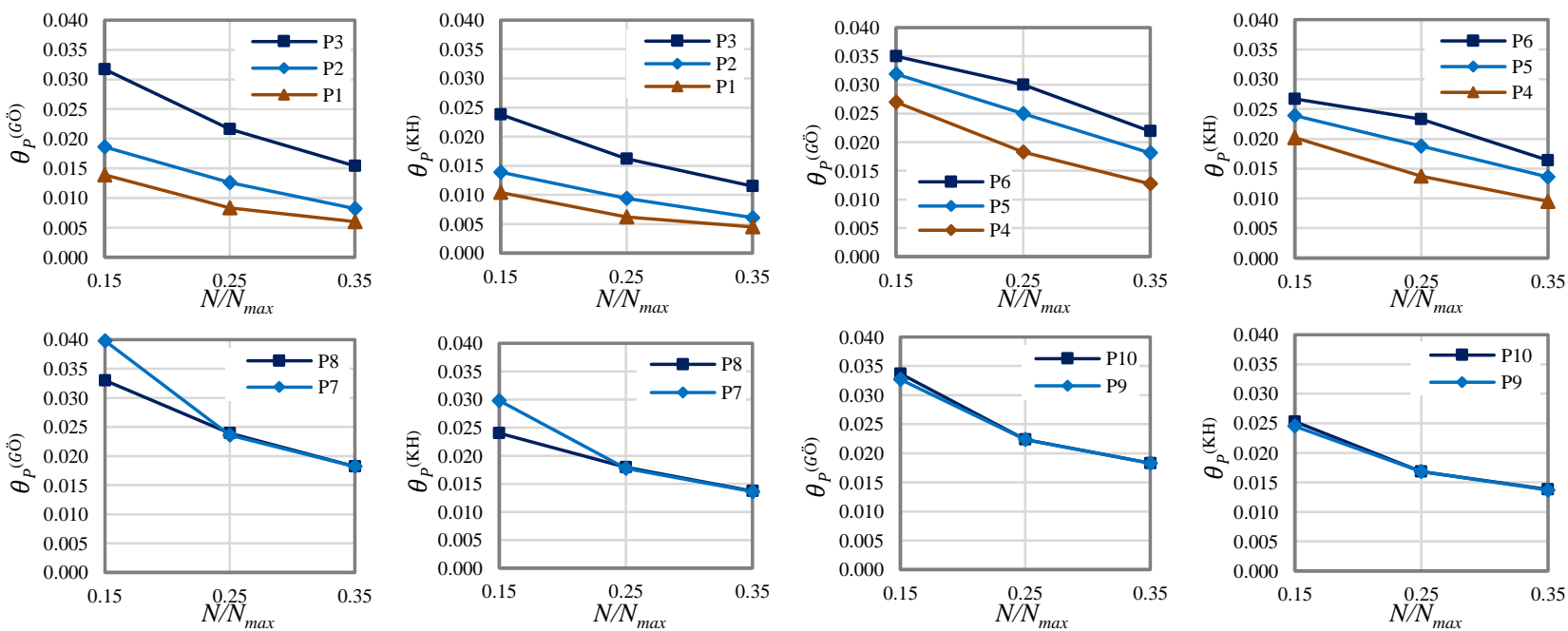

Şekil 6. Betonarme perde duvarların N/N_max $-\theta \_p$ ilişkileri 

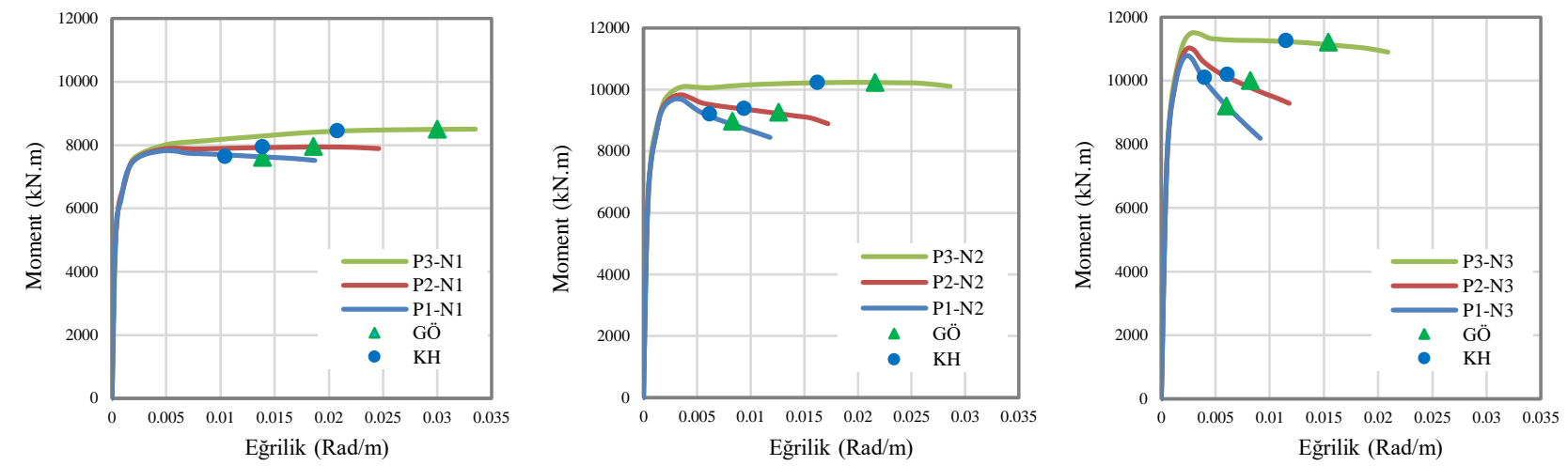

Şekil 7. Farklı yatay donatı aralığına sahip perdelerin moment-eğrilik ilişkileri ve hasar sınırları
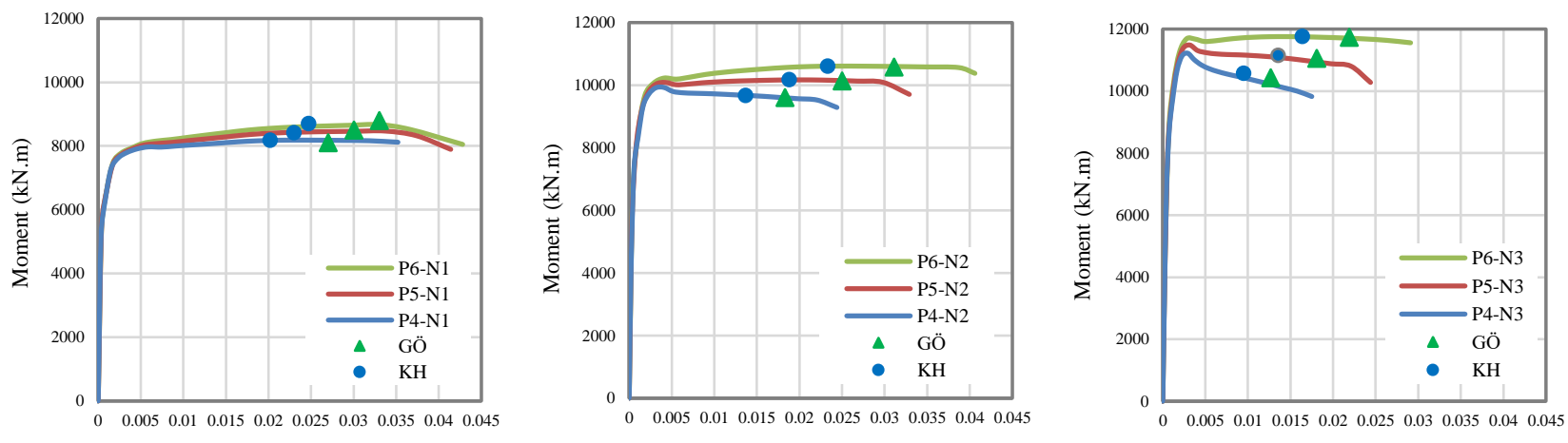

Eğrilik $(\operatorname{Rad} / \mathrm{m})$

Eğrilik $(\operatorname{Rad} / \mathrm{m})$

Eğrilik $(\operatorname{Rad} / \mathrm{m})$

Şekil 8. Farklı yatay donatı çapına sahip perdelerin moment-eğrilik ilişkileri ve hasar sınırları
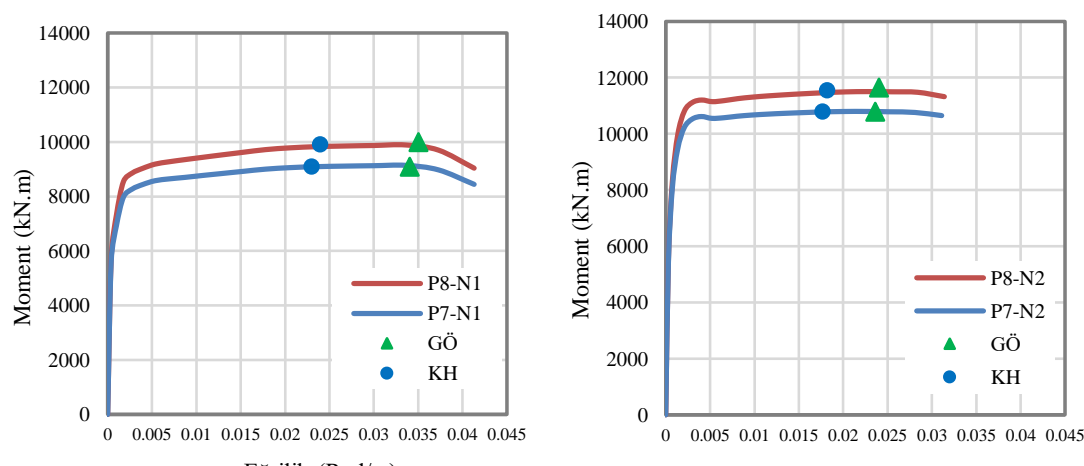

Eğrilik (Rad/m)

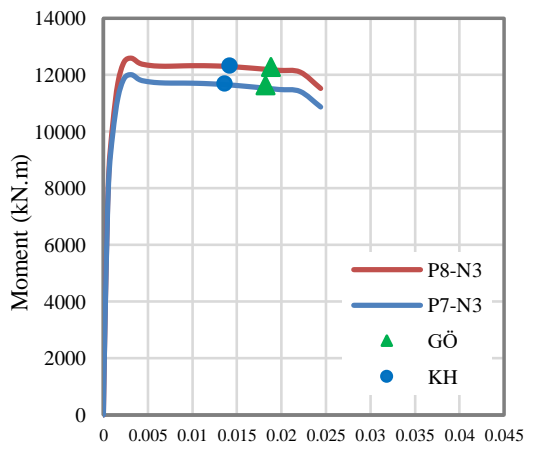

Eğrilik (Rad/m)

Şekil 9. Perde duvar uç bölgelerindeki farklı boyuna donatı çapına sahip perdelerin moment-eğrilik ilişkileri ve hasar sinırları

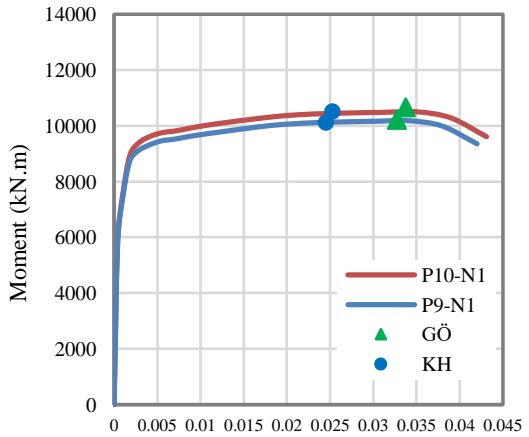

Eğrilik $(\operatorname{Rad} / \mathrm{m})$

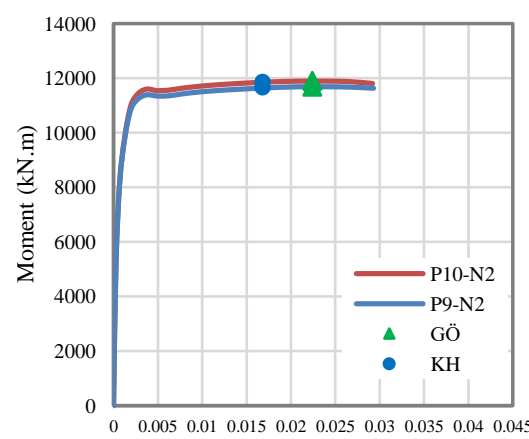

Eğrilik $(\operatorname{Rad} / \mathrm{m})$

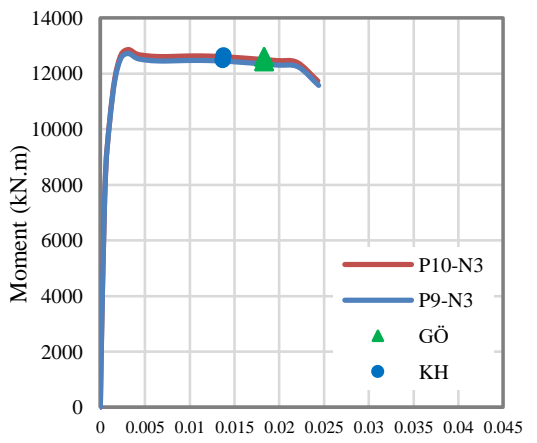

Eğrilik $(\operatorname{Rad} / \mathrm{m})$

Şekil 10. Perde duvar gövde bölgelerindeki farklı boyuna donatı çapına sahip perdelerin moment-eğrilik ilişkileri ve hasar sınırları 


\section{Sonuçlar}

Perde duvarlarda yatay donatı oranının artmasıyla $\varepsilon_{c}^{(G O ̈)}, \varepsilon_{c}^{(K H)}$ değerleri artmakta ve $\varepsilon_{c}^{(S H)}=0.0025$ olarak sabittir. Boyuna donatı oranının artması sargılı beton basınç dayanımını fazla etkilemediği için hesaplanan beton birim şekildeğiştirme $\left(\varepsilon_{c}\right)$ değerlerini etkilememiştir. Sabit yatay donatı oranı için boyuna donatı oranının $\operatorname{artmas}$ ile $\varepsilon_{c}^{(G O ̈)}$ ve $\varepsilon_{c}^{(K H)}$ değerleri sabit kalmaktadır. Farklı boyuna ve yatay donatı oranına göre hesaplanan $\varepsilon_{s}^{(G O ̈)}, \varepsilon_{s}^{(K H)}$ ve $\varepsilon_{s}^{(S H)}$ değerleri sabit kalmaktadır. $\theta_{p}^{(G O ̈)}$ ve $\theta_{p}^{(K H)}$ sinır değerleri $N / N_{\text {max }}$ değeri ve momenteğrilik ilişkisine göre değişmektedir. $N / N_{\text {max }}$ değerinin artmasıyla $\theta_{p}^{(G O ̈)}$ ve $\theta_{p}^{(K H)}$ sınır değerleri azalmaktadır. Sabit $N / N_{\text {max }}$ değeri, boyuna ve yatay donatı çapı için yatay donatı aralığının artması ile $\theta_{p}^{(G O ̈)}$ ve $\theta_{p}^{(K H)}$ sınır değerleri azalmaktadır. Sabit boyuna donatı çapı, yatay donatı aralığı ve $N / N_{\max }$ değeri için yatay donatı çapının artması ile $\theta_{p}^{(G O ̈)}$ ve $\theta_{p}^{(K H)}$ sınır değerleri artmaktadır. Sabit $N / N_{\max }$ değeri, yatay donatı çapı ve aralığı ve için boyuna donatı çapının artması ile $\theta_{p}^{(G O ̈)}$ ve $\theta_{p}^{(K H)}$ sınır değerleri az farkla artmaktadır. $N / N_{\max }$ değeri arttıkça hasar sınır değerleri azalmakta, bu yük seviyelerinde yatay donatı oranının daha da önemli olduğu ve yönetmeliğin öngördüğü sınırlamanın son derece etkili olduğu sonuçlarına varılmaktadır. Hesaplanan hasar sınırı değerleri ve bölgeleri perde duvarların moment-eğrilik ilişkileri üzerinde işlenmiştir. Moment-eğrilik ilişkilerinden hesaplanan hasar sınırları ve bölgelerinden görüleceği gibi perde duvarlarda yatay donatı oranının artması sonucunda perde duvar kesitleri daha güvenli yönde kalmaktadır.

\section{Teşekkür}

Yazarlar; zaman ayırdıkları, kıymetli yorum ve önerilerde bulundukları için makaleyi değerlendiren hakemlere teşekkür etmektedir.

\section{Yazar Katkıları}

Çalışma ile ilgili analiz planı, betonarme perde duvar modellerinin tasarlanması, veri toplanması, istatistiksel analizlerin yapılması, elde edilen sonuçların değerlendirilmesi ve makalenin yazılması birinci ve ikinci yazar tarafından paylaşılarak yapılmıştır.

\section{Çıkar Çatışması}

Yazarlar tarafından herhangi bir çıkar çatışması beyan edilmemiştir.

\section{Kaynaklar}

Bohl, A. and Adebar, P. (2011). Plastic hinge lengths in high-rise concrete shear walls. ACI Structure Journal, 108(2), 148-157. doi: https://doi.org/10.14288/1.0063296.

Foroughi, S. and Yuksel, S. B. (2020a). Investigation of the Moment-Curvature Relationship for Reinforced Concrete Square Columns. Turkish Journal of Engineering, 4(1), 36-46. doi: https://doi.org/10.31127/tuje.571598.

Foroughi, S. and Yuksel, S. B. (2020b). Analytical Investigation of Curvature Ductility of Reinforced Concrete Columns. Uludağ University Journal of the Faculty of Engineering, 25(1), 27-38. doi: https://doi.org/10.17482/uumfd.510862.

Foroughi, S and Yüksel, S. B. (2020c). Investigation of nonlinear behavior of high ductility reinforced concrete shear walls. International Advanced Researches and Engineering Journal, 4(2), 116-128. doi: https://doi.org/10.35860/iarej.693724.

Foroughi, S. ve Yüksel, S. B. (2019). Betonarme kolonların şekildeğiştirme esaslı hasar sınırlarının araştırılması. Uluslararası Mühendislik Araştırma ve Geliştirme Dergisi (UMAGD), 11(2), 584-601. doi: https://doi.org/10.29137/umagd.519208.

Kazaz, İ., Gülkan, P., and Yakut, A. (2012a). Performance limits for structural walls: An analytical perspective, Engineering $\quad$ Structures, $\quad 43, \quad 105-119 . \quad$ doi: https://doi.org/10.1016/j.engstruct.2012.05.011. 
Kazaz, İ., Gülkan, P.and Yakut, A. (2012b). Deformation limits for structural walls with confined boundaries. Earthquake Spectra, 28(3), 1019-1046. doi: https://doi.org/10.1193/1.4000059

Karageyik, C. and Sucuoğlu, H. (2011). Betonarme binaların perdelerle güçlendirilmesinde şekildeğiştirme esaslı yöntemlerin uygulanması. 1. Türkiye Deprem Mühendisliği ve Sismoloji Konferansı. (pp. 1-10) 11-14 Ekim 2011-ODTÜ-Ankara. Erişim adresi: https://docplayer.biz.tr/18184862-Betonarmebinalarin-perdelerle-guclendirilmesinde-sekildegistirme-esasli-yontemlerin-uygulanmasi.html.

Moehle, J. P. (1992). Displacement-based design of RC structures subjected to earthquakes. Earthquake Spectra. 8(3), 403-428. doi: https://doi.org/10.1193/1.1585688.

Mander, J B., Priestley, M. J. N., and Park, R. (1988). Theoretical stress-strain model for confined concrete. Journal of Structural Engineering (ASCE), 114(8), 1804-1826. doi: https://doi.org/10.1061/ (ASCE)0733-9445(1988)114:8(1804).

Özdemir, M. A., Kazaz, İ. and Özkaya, S. G. (2017). Evaluation and comparison of ultimate deformation limits for RC columns. Engineering Structures, 153, p. 569-581. doi: https://doi.org/10.1016/ j.engstruct.2017.10.050

Perez, J. C. V. and M. M. Mulder. (2018). Improved procedure for determining the ductility of buildings under seismic loads, Revista Internacional de Metodos Numericos para Calculoy Diseno en Ingenieria, 34(1), 1-8. doi: https://doi.org/10.23967/j.rimni.2018.03.001.

Panagiotakos, T. B. and Fardis, M. N. (1999). Estimation of inelastic deformation demands in multistory RC frame buildings. Journal of Earthquake Engineering. 3(4), 495-518. doi: https://doi.org/10.1002/ (SICI)1096-9845(199905)28:5<501::AID-EQE827>3.0.CO;2-5.

Qian, Jia-ru., and Xu, Fu-jiang. (2007). Displacement-based deformation capacity design method of RC cantilever walls. Journal of Tsinghua University: Science and Technology. 47(3): 305-308. Erişim adresi: https://en.cnki.com.cn/Article_en/CJFDTOTAL-QHXB200703000.htm.

Priestley, M. J. N., Calvi, G. M., Kowalsky, M. J. and Powell, G. H. (2008). Displacement-based seismic design of structures. Earthquake Spectra, 24(2). doi: https://doi.org/10.1193/1.2932170.

Rutenberg, A. and Nsieri, E. (2006). The seismic shear demand in ductile cantilever wall systems and the EC8 Provisions. Bulletin of Earthquake Engineering, 4, 1-21. doi: https://doi.org/10.1007/s10518-005-5407-9.

SAP, 2000. Structural Software for Analysis and Design, Computers and Structures, Inc. Version 20.2.0. USA.

Tjhin, T. N., Ascheim, M. A. and Wallace, J. W. (2007). Yield displacement-based seismic design of RC wall buildings. Engineering Structures, 29(11), 2946-2959. doi: https://doi.org/10.1016/ j.engstruct.2006.10.022.

Taleb, R., Watanabe, H. and Kono, S. (2018). Numerical study on the ultimate deformation of RC structural walls with confined boundary regions. Periodica Polytechnica Civil Engineering. 62(1), 191-199. doi: https://doi.org/10.3311/PPci.10554.

TS500. (2000). Betonarme Yapıların Tasarım ve Yapım Kuralları. Türk Standartları Enstitüsü, Ankara, Türkiye. Erişim adresi: http://www.iibh.org/kijun/pdf/Turkey_06.pdf.

TBDY. (2018). Türkiye Bina Deprem Yönetmeliği. T.C. Bayındırlık ve İskân Bakanlığı, Ankara, Türkiye. Erişim adresi: https://www.resmigazete.gov.tr/eskiler/2018/03/20180318M1-2-1.pdf.

Wallace, J. W. and Moehle, J. P. (1992). Ductility and detailing requirements of bearing wall buildings, ASCE Journal of Structural Engineering, 118(6), 1625-1644. doi: https://doi.org/10.1061/(ASCE)0733-9445(1992)118:6(1625).

Xiao-chun, L. and Xiao-lei, H. (2011). Performance index limits of high reinforced concrete shear wall components. Journal of the Central South University of Technology. 18, 1248-1255. doi: https://doi.org/10.1007/s11771-011-0829-9.

Xin, Li., Liang, Xing-wen. and Deng, Ming-ke. (2009). Plastic hinge rotation-based design method of shear walls boundary elements. Industrial Construction, 39(6), 50-64. Erişim adresi: https://en.cnki.com.cn/Article_en/CJFDTotal-GYJZ200906014.htm.

Zhou, Y., Zhang, D., Huang, Z. and Li, D. (2014). Deformation capacity and performance-based seismic design for reinforced concrete shear walls. Journal of Asian Architecture and Building Engineering, 13(1), 209-215. doi: https://doi.org/10.3130/jaabe.13.209.

Zhang, Hong-mei., Lu, Xi-lin., Yang, Xue-ping., and Zhang, song. (2008). Influence of boundary stirrup on seismic behavior of reinforced concrete shear walls. Structural Engineers, 24(5), 100-118. Erişim adresi: https://en.cnki.com.cn/Article_en/CJFDTotal-JGGC200805018.htm. 